\title{
Data Dependence of Noor and SP Iterative Schemes when dealing with Quasi-Contractive Operators
}

\author{
Renu Chugh and Vivek Kumar \\ Department of Mathematics \\ Maharshi Dayanand University \\ Rohtak, India
}

\begin{abstract}
We prove results concerning data dependence of Noor and SP iterative schemes using certain quasi-contractive operators in real Banach spaces. Our results reveal that by choosing an approximate quasi-contractive operator (for which it is possible to compute the fixed point); we can approximate the fixed point of the given operator. An example is also provided to explain the validity of our results.
\end{abstract}

\section{General Terms}

Computational Mathematics

\section{Keywords}

SP iteration, Noor iteration, Quasi-Contractive Operators

\section{INTRODUCTION}

Let $E$ be a real Banach space and $B$ be a nonempty closed, convex subset of $E$. Let $T, S$ be two self operators on $B$.

In a complete metric space, the Picard iterative process $\left\{x_{n}\right\}_{n=0}^{\infty}$ defined by

$$
x_{n+1}=T x_{n} n=0,1, \ldots
$$

has been employed to approximate the fixed points of mappings satisfying the inequality

$$
d(T x, T y) \leq \alpha d(x, y)
$$

for all $x, y \in X$ and $\alpha \in[0,1)$.

Condition (1.2) is called the Banach's contraction condition. Any operator satisfying (1.2) is called a strict contraction. In 1953, W.R. Mann defined the Mann iteration [8] as

$$
u_{n+1}=\left(1-\alpha_{n}\right) u_{n}+\alpha_{n} T u_{n},
$$

where $\left\{\alpha_{\mathrm{n}}\right\}$ is a sequences of positive numbers in $[0,1]$. In 1974, S. Ishikawa defined the Ishikawa iteration [7] as

$$
\begin{aligned}
s_{n+1} & =\left(1-\alpha_{n}\right) s_{n}+\alpha_{n} T t_{n} \\
t_{n} & =\left(1-\beta_{n}\right) s_{n}+\beta_{n} T s_{n},
\end{aligned}
$$

where $\left\{\alpha_{\mathrm{n}}\right\}$ and $\left\{\beta_{\mathrm{n}}\right\}$ are sequences of positive numbers in $[0,1]$.
For a given $x_{0} \in B$ and $u_{0} \in B$, we consider the Noor iteration [9] for operators $S$ and $T$ as

$$
\begin{aligned}
& x_{n+1}=\left(1-\alpha_{n}\right) x_{n}+\alpha_{n} T y_{n}, \quad y_{n}=\left(1-\beta_{n}\right) x_{n}+\beta_{n} T z_{n}, \\
& z_{n}=\left(1-\gamma_{n}\right) x_{n}+\gamma_{n} T x_{n}, \\
& u_{n+1}=\left(1-\alpha_{n}\right) u_{n}+\alpha_{n} S v_{n}, v_{n}=\left(1-\beta_{n}\right) u_{n}+\beta_{n} S w_{n}, \\
& w_{n}=\left(1-\gamma_{n}\right) u_{n}+\gamma_{n} S u_{n},
\end{aligned}
$$

where $\left\{\alpha_{\mathrm{n}}\right\},\left\{\beta_{\mathrm{n}}\right\}$ and $\left\{\gamma_{\mathrm{n}}\right\}$ are sequences of positive numbers in $[0,1]$ satisfying $\lim _{n \rightarrow \infty} \alpha_{n}=\lim _{n \rightarrow \infty} \beta_{n}=0, \quad \sum_{n=0}^{\infty} \alpha_{n}=\infty$.

Also, for a given $x_{0} \in B$ and $u_{0} \in B$, we consider SP iteration [12] for operators $S$ and $T$ as

$$
\begin{array}{ll}
x_{n+1}=\left(1-\alpha_{n}\right) y_{n}+\alpha_{n} T y_{n}, & y_{n}=\left(1-\beta_{n}\right) z_{n}+\beta_{n} T z_{n}, \\
z_{n}=\left(1-\gamma_{n}\right) x_{n}+\gamma_{n} T x_{n}, & \\
u_{n+1}=\left(1-\alpha_{n}\right) v_{n}+\alpha_{n} S v_{n}, & v_{n}=\left(1-\beta_{n}\right) w_{n}+\beta_{n} S w_{n}, \\
w_{n}=\left(1-\gamma_{n}\right) u_{n}+\gamma_{n} S u_{n}, &
\end{array}
$$

where $\left\{\alpha_{\mathrm{n}}\right\},\left\{\beta_{\mathrm{n}}\right\}$ and $\left\{\gamma_{\mathrm{n}}\right\}$ are sequences of positive numbers in $[0,1]$ satisfying $\beta_{n} \leq \alpha_{n}, \gamma_{n} \leq \alpha_{n}, \sum_{n=0}^{\infty} \alpha_{n}=\infty$.

\section{Remarks}

1. If $\gamma_{\mathrm{n}}=0$, then Noor iteration (1.5) reduces to the Ishikawa iteration (1.4).

2. If $\beta_{\mathrm{n}}=\gamma_{\mathrm{n}}=0$, then Noor iteration (1.5) reduces to the Mann iteration (1.3).

3. If $\beta_{\mathrm{n}}=\gamma_{\mathrm{n}}=0$, then SP iteration (1.7) reduces to the Mann iteration (1.3)

Several authors $[1,4,12-20]$ have studied the convergence of various iterative schemes. In 1972, Zamfirescu [20] obtained the following interesting fixed point theorem:

Theorem 1.1.[20] Let $(E, d)$ be a complete metric space and $T: E \rightarrow E$ a mapping for which there exists real numbers $a, b$ 
and $c$ satisfying $a \in(0,1), b, c \in\left(0, \frac{1}{2}\right)$ such that for each pair $x, y \in E$ at least one of the following conditions hold

(i) $d(T x, T y) \leq a d(x, y)$

(ii) $d(T x, T y) \leq b[d(x, T x)+d(y, T y)]$

(iii) $d(T x, T y) \leq c[d(x, T y)+d(y, T x)]$

Then $T$ has a unique fixed point $p$ and the Picard iteration $\left\{x_{n}\right.$ \}

defined by

$$
x_{n+1}=T x_{n}, n=0,1, \ldots
$$

converges to $p$ for any arbitrary but fixed $x_{0} \in E$.

The operators satisfying the condition (1.9) are called Zamfirescu operators.

Berinde[1] introduced a new class of operators on an arbitrary Banach space satisfying

$$
d(T x, T y) \leq 2 \delta d(x, T x)+\delta d(x, y)
$$

$\forall x, y \in E$ and $\delta \in[0,1)$.

He proved that this class is wider than the class of Zamfirescu operators and used the Ishikawa iteration process to approximate fixed points of this class of operators in an arbitrary Banach space given in the form of following theorem.

Theorem 1.2[1] Let $K$ be a nonempty closed convex subset of an arbitrary Banach space $E$ and $T: K \rightarrow K$ a mapping satisfying (1.9). Let $\left\{s_{n}\right\}_{n=0}^{\infty}$ be defined through the Ishikawa iteration (1.4) and $x_{0} \in K$, where $\left\{\alpha_{\mathrm{n}}\right\},\left\{\beta_{\mathrm{n}}\right\}$ are sequences of positive numbers in $[0,1]$ with $\left\{\alpha_{\mathrm{n}}\right\}$ satisfying $\sum_{n=0}^{\infty} \alpha_{n}=\infty$. Then $\left\{s_{n}\right\}_{n=0}^{\infty}$ converges strongly to the fixed point of $T$.

Rafiq [14] studied the convergence of the three step iteration process for quasi-contractive operators. Osilike [10] generalized and extended some of the results of Rhoades [15] by using the following more general contractive definition than (1.10): there exist $q \in[0,1), L \geq 0$ such that

$$
d(T \mathrm{x}, T y) \leq L d(x, T x)+q d(\mathrm{x}, y), \forall x, y \in E
$$

He established the stability of Picard, Mann, Ishikawa and Noor iterative schemes using (1.11).

Imoru and Olatinwo [6] proved the stability of the Picard and the Mann iteration process for the following operator which is more general than the one introduced by Osilike [10].The operator satisfies the following contractive definition : there exist $q \in[0,1)$ and a monotone increasing function $\varphi$ : $R^{+} \rightarrow R^{+}$with $\varphi(0)=0$, such that

$$
d(T x, T y) \leq \varphi(d(x, T x))+q d(x, y), \forall x, y \in E
$$

Since the metric is induced by norrn, above contractive condition can be written as

$$
\|T x-T y\| \leq \varphi(\|x-T x\|)+q\|x-y\|, \quad \forall x, y \in X
$$

Olaleru and Akewe [11] proved the convergence of Jungck type iterations for generalized contractive-like operators in Banach space. Renu Chugh and Vivek Kumar [4] proved the convergence of Jungck-SP iterative scheme using quasicontractive operators satisfying (1.12).

\section{Remarks}

4. Putting $X=Y$ and $S=I$ (identity mapping) in Corollary 2 of Theorem 2 [11], convergence of Noor iteration to a fixed point of quasi-contractive operators satisfying (1.12) can be obtained easily.

5. Putting $X=Y, L=0$ and $S=I$ (identity mapping) in Theorem 4.1 [4], convergence of SP iteration to a fixed point of quasi-contractive operators satisfying (1.12) can be obtained easily.

\section{PRELIMINARIES}

The results on data dependence for Picard iteration are in $[2$, 16]. Data dependence for Mann and Ishikawa iterations using contraction condition (1.2) was proved by Solutz in $[17,18]$. Data dependence for Ishikawa iterations when dealing with contractive like operators satisfying (1.12) was proved by Solutz in [19].

In 2010, by providing an example Ciric et al.[5] proved that Noor iteration can have a better covergence rate as compared to Mann

and Ishikawa iterative schemes. In 2011, W. Pheungrattana and S. Suantai [12] defined SP iterative scheme and proved that this iterative scheme converges faster than Mann, Ishikawa and Noor iterative schemes for increasing functions. This is the main reason for considering Noor and SP iterative schemes in this paper.

Motivated by the work of Solutz[17-19], in this paper we prove the data dependence results for Noor and SP iterative schemes using the quasi-contractive operators satisfying (1.12). An example is also provided to explain the results.

We shall need the following Lemma to prove our results. 
Lemma 2.1.[19] Let $\left\{a_{n}\right\}_{n=0}^{\infty}$ be a nonnegative sequence for which one suppose there exist $n_{0} \in N$ such that for all $n \geq n_{0}$ one has satisfied the following inequality :

$$
a_{n+1} \leq\left(1-r_{n}\right) a_{n}+r_{n} t_{n},
$$

where $r_{n} \in(0,1)$, for all $n \in N, \sum_{n=1}^{\infty} r_{n}=\infty$ and $t_{n} \geq 0 \quad \forall n \in N$. Then ,

$0 \leq \limsup _{n \rightarrow \infty} a_{n} \leq \lim _{n \rightarrow \infty} \sup t_{n}$.

\section{MAIN RESULTS}

First we prove the result on data dependence for Noor iterative scheme.

Theorem 3.1. Let $K$ be a nonempty convex, closed subset of a real Banach space $E$ and $T: K \rightarrow K$ a quasi-contractive operator satisfying (1.12). Let $S$ be an approximate operator of $T$ i.e.

$$
\|T x-S x\| \leq \varepsilon
$$

for all $x \in K, \varepsilon>0$ and $\left\{x_{n}\right\}_{n=0}^{\infty},\left\{u_{n}\right\}_{n=0}^{\infty}$ be the Noor iterations associated to $T$, respectively to $S$, starting from $x_{0}$. If $T x^{*}=x^{*}$ and $S u^{*}=u^{*}\left(u^{*}\right.$ taken nearest to $\left.x^{*}\right)$, then we have

$$
\left\|x^{*}-u^{*}\right\| \leq \frac{\varepsilon}{1-q}
$$

Proof. It follows from (1.5) and (1.6) that

$$
\begin{gathered}
\left\|x_{n+1}-u_{n+1}\right\| \leq\left(1-\alpha_{n}\right)\left\|x_{n}-u_{n}\right\|+\alpha_{n}\left\|T y_{n}-S v_{n}\right\| \\
\leq\left(1-\alpha_{n}\right)\left\|x_{n}-u_{n}\right\|+\alpha_{n}\left\|T y_{n}-T v_{n}\right\| \\
+\alpha_{n}\left\|T v_{n}-S v_{n}\right\| \\
\leq\left(1-\alpha_{n}\right)\left\|x_{n}-u_{n}\right\|+\alpha_{n} q\left\|y_{n}-v_{n}\right\| \\
+\alpha_{n} \varphi\left(\left\|y_{n}-T y_{n}\right\|\right)+\alpha_{n} \varepsilon \\
\leq\left(1-\alpha_{n}\right)\left\|x_{n}-u_{n}\right\|+\alpha_{n} \varepsilon+q \alpha_{n}\left(1-\beta_{n}\right)\left\|x_{n}-u_{n}\right\| \\
+q \alpha_{n} \beta_{n}\left\|T z_{n}-S w_{n}\right\|+\alpha_{n} \varphi\left(\left\|y_{n}-T y_{n}\right\|\right) \\
\leq\left(1-\alpha_{n}\right)\left\|x_{n}-u_{n}\right\|+\alpha_{n} \varepsilon+q \alpha_{n}\left(1-\beta_{n}\right)\left\|x_{n}-u_{n}\right\| \\
+q \alpha_{n} \beta_{n}\left\|T z_{n}-T w_{n}\right\|+q \alpha_{n} \beta_{n}\left\|T w_{n}-S w_{n}\right\| \\
\quad+\alpha_{n} \varphi\left(\left\|y_{n}-T y_{n}\right\|\right) \\
\leq\left(1-\alpha_{n}\right)\left\|x_{n}-u_{n}\right\|+\alpha_{n} \varepsilon+\alpha_{n} q\left(1-\beta_{n}\right)\left\|x_{n}-u_{n}\right\| \\
+q^{2} \alpha_{n} \beta_{n}\left\|z_{n}-w_{n}\right\|+q \alpha_{n} \beta_{n} \varphi\left(\left\|z_{n}-T z_{n}\right\|\right) \\
\quad+q \alpha_{n} \beta_{n} \varepsilon+\alpha_{n} \varphi\left(\left\|y_{n}-T y_{n}\right\|\right) \\
\leq\left[1-\alpha_{n}+\alpha_{n} q\left(1-\beta_{n}\right)\right]\left\|x_{n}-u_{n}\right\|+\alpha_{n} \varepsilon \\
+q^{2} \alpha_{n} \beta_{n}\left(1-\gamma_{n}\right)\left\|x_{n}-u_{n}\right\| \\
+q^{2} \alpha_{n} \beta_{n} \gamma_{n}\left\|T x_{n}-S u_{n}\right\|+q \alpha_{n} \beta_{n} \varphi\left(\left\|z_{n}-T z_{n}\right\|\right) \\
+q \alpha_{n} \beta_{n} \varepsilon+\alpha_{n} \varphi\left(\left\|y_{n}-T y_{n}\right\|\right)
\end{gathered}
$$

$$
\begin{aligned}
\leq & {\left[1-\alpha_{n}+\alpha_{n} q\left(1-\beta_{n}\right)\right]\left\|x_{n}-u_{n}\right\|+\alpha_{n} \varepsilon } \\
& +q^{2} \alpha_{n} \beta_{n}\left(1-\gamma_{n}\right)\left\|x_{n}-u_{n}\right\| \\
& +q^{2} \alpha_{n} \beta_{n} \gamma_{n}\left\|T x_{n}-T u_{n}\right\|+q^{2} \alpha_{n} \beta_{n} \gamma_{n} \varepsilon \\
& +q \alpha_{n} \beta_{n} \varphi\left(\left\|z_{n}-T z_{n}\right\|\right)+q \alpha_{n} \beta_{n} \varepsilon+\alpha_{n} \varphi\left(\left\|y_{n}-T y_{n}\right\|\right)
\end{aligned}
$$

$$
\begin{gathered}
\leq\left[1-\alpha_{n}+\alpha_{n} q\left(1-\beta_{n}\right)\right]\left\|x_{n}-u_{n}\right\|+\alpha_{n} \varepsilon \\
+q^{2} \alpha_{n} \beta_{n}\left(1-\gamma_{n}\right)\left\|x_{n}-u_{n}\right\| \\
+q^{3} \alpha_{n} \beta_{n} \gamma_{n}\left\|x_{n}-u_{n}\right\|+q^{2} \alpha_{n} \beta_{n} \gamma_{n} \varphi\left(\left\|x_{n}-T x_{n}\right\|\right. \\
+q^{2} \alpha_{n} \beta_{n} \gamma_{n} \varepsilon++q \alpha_{n} \beta_{n} \varphi\left(\left\|z_{n}-T z_{n}\right\|\right) \\
\quad+q \alpha_{n} \beta_{n} \varepsilon+\alpha_{n} \varphi\left(\left\|y_{n}-T y_{n}\right\|\right)
\end{gathered}
$$

$$
\begin{aligned}
=[1 & \left.-\alpha_{n}(1-q)-\alpha_{n} \beta_{n} q(1-q)-\alpha_{n} \beta_{n} \gamma_{n} q^{2}(1-q)\right]\left\|x_{n}-u_{n}\right\| \\
& +\frac{\alpha_{n}(1-q)\left[q^{2} \beta_{n} \gamma_{n} \varphi\left(\left\|x_{n}-T x_{n}\right\|\right)+q \beta_{n} \varphi\left(\left\|z_{n}-T z_{n}\right\|\right)\right]}{1-q} \\
& +\frac{\alpha_{n}(1-q)\left[\varphi\left(\left\|y_{n}-T y_{n}\right\|\right)+q^{2} \beta_{n} \gamma_{n} \varepsilon+q \beta_{n} \varepsilon+\varepsilon\right]}{1-q}
\end{aligned}
$$

Now, $\varphi$ is a continuous mapping and $\left\{x_{n}\right\},\left\{y_{n^{-}}\right.$

\},$\left\{z_{n}\right\}$, converges

to a fixed point of $T$ (using Remark 4), hence $\lim _{n \rightarrow \infty} \varphi\left(\left\|x_{n}-T x_{n}\right\|\right)=\lim _{n \rightarrow \infty} \varphi\left(\left\|y_{n}-T y_{n}\right\|\right)=\lim _{n \rightarrow \infty} \varphi\left(\left\|z_{n}-T z_{n}\right\|\right)=0$. Putting $r_{n}=\alpha_{n}(1-q)$ and

$$
\begin{array}{r}
t_{n}=\frac{q^{2} \beta_{n} \gamma_{n} \varphi\left(\left\|x_{n}-T x_{n}\right\|\right)+q \beta_{n} \varphi\left(\left\|z_{n}-T z_{n}\right\|\right)}{1-q} \\
+\frac{\varphi\left(\left\|y_{n}-T y_{n}\right\|\right)+q^{2} \beta_{n} \gamma_{n} \varepsilon+q \beta_{n} \varepsilon+\varepsilon}{1-q}
\end{array}
$$

in (3.1) and using Lemma (2.1), we get

$\left\|x^{*}-u^{*}\right\| \leq \frac{\varepsilon}{1-q} . \quad$ Hence the result.

Now, we prove the result on data dependence for SP iterative scheme.

Theorem 3.2. Let $K$ be a nonempty convex, closed subset of a real Banach space $E$ and $T: K \rightarrow K \quad a$ quasi-contractive operator satisfying (1.12). Let $S$ be an approximate operator of $T$ i.e.

$$
\|T x-S x\| \leq \varepsilon
$$

for all $x \in K, \varepsilon>0$ and $\left\{x_{n}\right\}_{n=0}^{\infty},\left\{u_{n}\right\}_{n=0}^{\infty}$ be the SP iterations associated to $T$, respectively to $S$, starting from $x_{0}$. If $T x^{*}=x^{*}$ and $S u^{*}=u^{*}\left(u^{*}\right.$ taken nearest to $\left.x^{*}\right)$, then we have

$$
\left\|x^{*}-u^{*}\right\| \leq \frac{3 \varepsilon}{1-q}
$$

Proof. It follows from (1.7) and (1.8) that 


$$
\begin{gathered}
\left\|x_{n+1}-u_{n+1}\right\| \leq\left(1-\alpha_{n}\right)\left\|y_{n}-v_{n}\right\|+\alpha_{n}\left\|T y_{n}-S v_{n}\right\| \\
\leq\left(1-\alpha_{n}\right)\left\|y_{n}-v_{n}\right\|+\alpha_{n}\left\|T y_{n}-T v_{n}\right\| \\
\quad+\alpha_{n}\left\|T v_{n}-S v_{n}\right\| \\
\leq\left(1-\alpha_{n}\right)\left\|y_{n}-v_{n}\right\|+\alpha_{n} q\left\|y_{n}-v_{n}\right\| \\
\quad+\alpha_{n} \varphi\left(\left\|y_{n}-T y_{n}\right\|\right)+\alpha_{n} \varepsilon \\
\leq\left(1-\alpha_{n}(1-q)\right)\left\|y_{n}-v_{n}\right\|+\alpha_{n} \varphi\left(\left\|y_{n}-T y_{n}\right\|\right) \\
\quad+\alpha_{n} \varepsilon
\end{gathered}
$$

Now, we have the following estimates :

$$
\begin{aligned}
&\left\|y_{n}-v_{n}\right\| \leq\left(1-\beta_{n}\right)\left\|z_{n}-w_{n}\right\| \\
& \leq \beta_{n}\left\|T z_{n}-S w_{n}\right\| \\
& \leq\left(1-\beta_{n}\right)\left\|z_{n}-w_{n}\right\|+\beta_{n}\left\|T z_{n}-T w_{n}\right\| \\
&+\beta_{n}\left\|T w_{n}-S w_{n}\right\| \\
& \leq\left(1-\beta_{n}\right)\left\|z_{n}-w_{n}\right\|+\beta_{n} q\left\|z_{n}-w_{n}\right\|+\beta_{n} \varphi\left(\left\|z_{n}-T z_{n}\right\|\right)+\beta_{n} \varepsilon \\
& \leq\left(1-\beta_{n}(1-q)\right)\left\|z_{n}-w_{n}\right\|+\beta_{n} \varphi\left(\left\|z_{n}-T z_{n}\right\|\right) \\
&+\beta_{n} \varepsilon
\end{aligned}
$$

and

$$
\begin{gathered}
\left\|z_{n}-w_{n}\right\| \leq\left(1-\gamma_{n}\right)\left\|x_{n}-u_{n}\right\|+\gamma_{n}\left\|T x_{n}-S u_{n}\right\| \\
\leq\left(1-\gamma_{n}\right)\left\|x_{n}-u_{n}\right\|+\gamma_{n}\left\|T x_{n}-T u_{n}\right\| \\
+\gamma_{n}\left\|T u_{n}-S u_{n}\right\| \\
\leq\left(1-\gamma_{n}\right)\left\|x_{n}-u_{n}\right\|+\gamma_{n} q\left\|x_{n}-u_{n}\right\| \\
+\gamma_{n} \varphi\left(\left\|x_{n}-T x_{n}\right\|\right)+\gamma_{n} \varepsilon \\
\leq\left(1-\gamma_{n}(1-q)\right)\left\|x_{n}-u_{n}\right\|+\gamma_{n} \varphi\left(\left\|x_{n}-T x_{n}\right\|\right) \\
+\gamma_{n} \varepsilon
\end{gathered}
$$

Substituting (3.3) and (3.4) in (3.2), we get

$$
\begin{gathered}
\leq\left[1-\alpha_{n}(1-q)\right]\left[1-\beta_{n}(1-q)\right]\left[1-\gamma_{n}(1-q)\right]\left\|x_{n}-u_{n}\right\| \\
+\alpha_{n} \varphi\left(\left\|y_{n}-T y_{n}\right\|\right)+\alpha_{n} \varepsilon \\
+\left[1-\alpha_{n}(1-q)\right] \beta_{n} \varphi\left(\left\|z_{n}-T z_{n}\right\|\right) \\
+\left[1-\alpha_{n}(1-q)\right] \beta_{n} \varepsilon \\
+\left[1-\alpha_{n}(1-q)\right]\left[1-\beta_{n}(1-q)\right] \gamma_{n} \varphi\left(\left\|x_{n}-T x_{n}\right\|\right) \\
+\left[1-\alpha_{n}(1-q)\right]\left[1-\beta_{n}(1-q)\right] \gamma_{n} \varepsilon \\
\leq\left[1-\alpha_{n}(1-q)\right]\left\|x_{n}-u_{n}\right\|+\alpha_{n} \varphi\left(\left\|y_{n}-T y_{n}\right\|\right)+\alpha_{n} \varepsilon \\
+\beta_{n} \varphi\left(\left\|z_{n}-T z_{n}\right\|\right)+\beta_{n} \varepsilon+\gamma_{n} \varphi\left(\left\|x_{n}-T x_{n}\right\|\right)+\gamma_{n} \varepsilon \\
\leq\left[1-\alpha_{n}(1-q)\right]\left\|x_{n}-u_{n}\right\| \\
+\frac{\alpha_{n}(1-q)\left[\varphi\left(\left\|y_{n}-T y_{n}\right\|\right)+\varphi\left(\left\|z_{n}-T z_{n}\right\|\right)\right]}{(1-q)} \\
+\frac{\alpha_{n}(1-q)\left[\varphi\left(\left\|x_{n}-T x_{n}\right\|\right)+3 \varepsilon\right]}{(1-q)}
\end{gathered}
$$

Now, $\varphi$ is a continuous mapping and $\left\{x_{n}\right\},\left\{y_{n}\right\},\left\{z_{n}\right\}$ converges to a fixed point of $T$ (using Remark 5), hence $\lim _{n \rightarrow \infty} \varphi\left(\left\|x_{n}-T x_{n}\right\|\right)=\lim _{n \rightarrow \infty} \varphi\left(\left\|y_{n}-T y_{n}\right\|\right)=\lim _{n \rightarrow \infty} \varphi\left(\left\|z_{n}-T z_{n}\right\|\right)=0$.
Putting $r_{n}=\alpha_{n}(1-q)$,

$t_{n}=\frac{\varphi\left(\left\|y_{n}-T y_{n}\right\|\right)+\varphi\left(\left\|z_{n}-T z_{n}\right\|\right)+\varphi\left(\left\|x_{n}-T x_{n}\right\|\right)+3 \varepsilon}{(1-q)}$

in (3.5) and using Lemma (2.1), we get

$\left\|x^{*}-u^{*}\right\| \leq \frac{3 \varepsilon}{1-q}$. Hence the result.

Remark 6. Since Mann and Ishikawa iterative schemes are special cases of Noor iterative scheme, data dependence results of these iterative schemes can be obtained similarly.

The following example follows from [19].

Example 3.1 Let $T: R \rightarrow R$ be defined by

$$
\begin{aligned}
T(x) & =0 \text { if } x \in(-\infty, 2] \\
& =-0.5 \text { if } x \in(2,+\infty)
\end{aligned}
$$

with unique fixed point 0 . Consider the mapping $S: R \rightarrow R$ defined by

$$
\begin{aligned}
S(x) & =1 \text { if } x \in(-\infty, 2] \\
& =-1.5 \text { if } x \in(2,+\infty)
\end{aligned}
$$

with unique fixed point 1 .

Take $\varepsilon=1$ such that $\|T x-S x\| \leq 1$.

Set $\mathrm{u}_{0}=\mathrm{x}_{0}=0$ and $\alpha_{n}=\beta_{n}=\gamma_{n}=\frac{1}{\sqrt{n+1}}$.

By using computer programs in $\mathrm{C}++$, Noor and SP iterative schemes leads to the following table . 


\begin{tabular}{|c|c|c|c|}
\hline $\begin{array}{l}\text { Number of } \\
\text { Iterations }\end{array}$ & $\begin{array}{l}\text { Noor } \\
\text { Iteration }\end{array}$ & $\begin{array}{l}\text { Number of } \\
\text { Iterations }\end{array}$ & SP Iteration \\
\hline 1 & 0.707107 & 1 & 0.974874 \\
\hline 2 & 0.876209 & 2 & 0.998103 \\
\hline 3 & 0.938104 & 3 & 0.999763 \\
\hline - & - & - & - \\
\hline 6 & 0.987406 & & 0.999998 \\
\hline 7 & 0.991858 & & 0.999999 \\
\hline 8 & 0.994572 & & 1 \\
\hline 9 & 0.996289 & & 1 \\
\hline - & - & - & - \\
\hline 47 & 0.999999 & & 1 \\
\hline 48 & 0.999999 & & 1 \\
\hline 49 & 0.999999 & & 1 \\
\hline 50 & 0.999999 & & 1 \\
\hline 51 & 1 & & 1 \\
\hline 52 & 1 & & 1 \\
\hline 53 & 1 & & 1 \\
\hline
\end{tabular}

Hence Noor and SP iterative schemes when applied to S converges to the fixed point $u^{*}=x^{*}=1$. Obviously distance between the fixed points is of $S$ and $T$ is 1 . Without computing the fixed point of $S$ (and without knowing it), from Theorem (3.1), we have the following estimate :

$$
\left\|x^{*}-u^{*}\right\| \leq \frac{1}{1-q}=\frac{1}{1-0.2}=1.2
$$

Also if $\varepsilon=\frac{1}{3}$, then using Theorem (3.2) we have the following estimate :

$\left\|x^{*}-u^{*}\right\| \leq \frac{1}{1-q}=\frac{1}{1-0.2}=1.2$

\section{CONCLUSION}

From Example 3.1, we conclude that instead of computing fixed points of $S$, if we choose $T$ more close to $S$, the distance between the fixed points of $S$ and $T$ will shrink too.

\section{ACKNOWLEDGMENTS}

The authors would like to thank to the referee for his/her careful reading of manuscript and their valuable comments.

\section{REFERENCES}

[1] Berinde, V. : On the convergence of the Ishikawa iteration in the class of quasi contractive operators, Acta Mathematica Universitatis Comenianae, vol. 73, no. 1, pp. 119-126( 2004).

[2] Berinde, V.: Generalized Contractions and Applications , (Romanian), Editura Cub press 22, Baia Mare (1997).

[3] Chidume, C. E and Mutangadura, S. A. : An example of the Mann iteration method for Lipschitz pseudocontractions, Proceedings of the American Mathematical Society, vol. 129, no. 8, pp. 2359-2363(2001).

[4] Chugh, Renu and Kumar, Vivek: Strong convergence of SP iterative scheme for quasi-contractive operators in Banach spaces, International Journal of Computer Applications, volume 31, No. 5, October (2011).

[5] Ciric, L.B., Lee, B. S. and Rafiq, A.: Faster Noor iterations, Indian Journal of Mathematics, T. Pati Memorial Volume, vol 52, no 3, 429-436(2010).

[6] Imoru ,C. O. and Olatinwo, M. O. : On the stability of Picard and Mann iteration processes, Carpathian Journal of Mathematics, vol. 19, no. 2, pp. 155-160(2003).

[7] Ishikawa, S. : Fixed points by a new iteration method, Proceedings of the American Mathematical Society, vol. 44, no. 1, pp. 147-150 (1974).

[8] Mann, W. R.: Mean value methods in iteration, Proceedings of the American Mathematical Society, vol. 4, no. 3, pp. 506-510( 1953).

[9] Noor, M. A. : New approximation schemes for general variational inequalities, Journal of Mathematical Analysis and Applications, vol. 251, no. 1, pp. 217-229(2000).

[10] Osilike, M.O., Some Stability Results for Fixed Point Iteration Procedures. J.Nigerian Math.Soc. Volume 14/15(1995), 17-29.

[11] Olaleru, J.O and Akewe. H.: The equivalence of Jungck type iterations for generalized contractive-like operators in Banach space , Fasciculi Mathematici ,47-61(2011).

[12] Phuengrattana, Withunand, Suantai, Suthep : On the rate of convergence of Mann, Ishikawa, Noor and SP iterations for continuous functions on an arbitrary interval, Journal of Computational and Applied Mathematics, 235(2011), 3006- 3014.

[13] Park, J. A.: Mann iteration process for the fixed point of strictly pseudocontractive mapping in some Banach spaces, Journal of the Korean Mathematical Society, vol. 31, no. 3, pp. 333-337(1994).

[14] Rafiq, A.: On the convergence of the three step iteration process in the class of quasi-contractive operators, Acta Mathematica Academiae Paedagogicae Nyiregyhaziensis, 22, 305-309(2006). 
[15] Rhoades, B.E., Fixed Point Theorems and Stability Results for Fixed Point Iteration Procedures II, Indian J. Pure Appl. Math. 24 (11) (1993), 691-703

[16] Rus, I.A. : Generalized Contractions and Applications , Cluj University Press, Cluj-Napoca(2001),3 pages.

[17] Ssoltuz, S. M.: Data dependence for Mann iteration, Octogon Math. Magazine 9 (2001), 825-828.
[18] Ssoltuz, S. M.: Data dependence for Ishikawa iteration, Lecturas Matematicas, vol. 25, no. 2, pp. 149-155, 2004.

[19] S,oltuz , S. M.: Data dependence for Ishikawa iteration when dealing with contractive like operators., Fixed Point Theory and Applications, Volume 2008, Article Id 242916, 7 pages.

[20] Zamfirescu, T.: Fix point theorems in metric spaces, Archiv derMathematik, vol. 23, no. 1, pp. 292-298(1972). 